\title{
Preschool Language and First-Grade Externalizing Behaviors: Gender Differences and the Longitudinal Mediation Through Self-Control
}

\author{
Jinna Chung \\ Assistant Professor, Department of Early Childhood Education, Yong-In Songdam College, Yongin, Korea \\ 5세 언어능력과 7세 외현화 문제행동의 관계: 성별 차이 및 자기통제의 \\ 종단적 매개효과 검증 \\ 정진나 \\ 용인송담대학교 유아교육과 조교수
}

Objectives: Building on prior research, this study aimed to test the proposition that child's selfcontrol would longitudinally mediate the link between preschool language ability and externalizing behavior problems in transition to school. Given a general pattern of gender differences previously found on each level of language ability, self-control, and externalizing behaviors, it was expected that the relations among these variables would be stronger in boys than in girls.

Methods: Data $(N=1,102)$ from 6th, 7th, and 8th wave of the Panel Study on Korean Children were used in the separate analyses for boys $(n=569)$ and girls $(n=533)$. The analyses were conducted using measures of receptive vocabulary (age 5), self-control (age 6), and overall externalizing behavior problems (age 7).

Results: The results showed that, after controlling for parental education and family income, child's selfcontrol fully mediated the relation between preschool language ability and first-grade externalizing behaviors for boys only.

Conclusion: The results provided support for the proposed mediation model in which preschool language is linked to later behavior problems via the development of self-control, and extended previous findings by showing that these relations were much stronger in boys.

Keywords: language ability, self-control, externalizing behavior problems, gender differences, longitudinal mediation

\section{Introduction}

어린 아동의 언어능력 즉, 어휘, 구문, 문해기술을 비롯한 다 양한 언어 관련 기술들은 아동기 전반에 걸쳐 부적응적 행동 문제와 관련되는 것으로 알려져 있다(Brownlie et al., 2004). 행 동 문제 중에서도 공격행동, 품행문제, 규칙위반행동 등과 같 이 부적절한 행동이 통제되지 않고 외부로 드러나는 외현화

Corresponding Author: Jinna Chung, Assistant Professor, Department of Early Childhood Education, Yong-In Songdam College, 61, Dongbu-ro, Cheoin-gu, Yongin-si, Gyeonggi-do, Korea

E-mail: jnchung@ysc.ac.kr
문제행동은 언어와의 관련성이 비교적 일관되게 보고된 영역 이다. 언어와 외현화 문제행동의 관계는 임상집단 아동(e.g., Cantwell \& Baker, 1991; Cohen et al., 2000)과 일반 아동(e.g., Beitchman et al., 2001; Park \& Kim, 2017) 모두의 경험자료를 통해 지지되었다. 최근의 메타분석(Yew \& O' Kearney, 2013)에 서도 발달 초기부터 나타난 언어적 결함이 이후 외현화 문제 의 발달을 설명하는 가장 주된 요인인 것으로 나타났다. 또한,

(C)The Korean Association of Child Studies

This is an Open Access article distributed under the terms of the Creative Commons Attribution Non-Commercial License (http:// creativecommons.org/licenses/by-nc/4.0) which permits unrestricted noncommercial use, distribution, and reproduction in any medium, provided the original work is properly cited. 
Petersen 등(2013)의 종단연구도 4세부터 12세 사이에 초기 언 어능력은 이후의 외현화 문제를 예측하지만, 초기 외현화 문제 는 이후의 언어능력을 예측하지 못한다는 것을 보여줌으로써 이 시기 언어발달이 외현화 문제행동 발달을 선행한다는 것을 보여주었다.

그러나 이러한 경험적 기반에 비해, 언어와 외현화 문제의 관계가 왜 나타나는지 그 기제에 대한 탐색은 아직 활발하게 이루어지지 못했다. Vygotsky와 Luria의 이론적 접근에 따르면, 언어는 어린 아동이 문제해결에서 자신의 행동을 사회적으로 바람직한 방향으로 이끌고 조절하도록 돕는다는 점에서 자기 통제(self-control)의 주요 도구가 된다(Fernyhough, 2010). 처음 에 어린 아동은 주로 부모의 언어적 지시나 안내에 의해 행동 을 조절한다. 그러나 유아기에 접어들면 혼잣말(private speech) 과 같은 언어적 발화를 통해 자신의 행동을 조절하고, 이후 점 차 혼잣말이 내면화됨에 따라 발화에 의존하지 않고도 내적 언 어(inner speech)를 사용하여 행동을 조절할 수 있게 된다. 따라 서 일반적 의미에서 아동의 내적 언어는 언어의 특정 측면만이 아닌, 언어능력 전반과 관련된다(Vygotsky, 1934/1987). 이러한 이론적 접근에 근거하면, 언어능력이 낮은 아동들은 내적 언어 를 잘 사용하지 못해 자신의 부적절한 행동을 효과적으로 조 절하거나 통제하는 데에도 어려움을 겪을 수 있다. 결과적으로 이들 아동은 행동 문제의 발달에서도 보다 높은 취약성을 지니 게 된다. Barkley (1997)도 행동 문제를 지닌 아동들에게 나타나 는 전형적인 자기통제적 결함이 언어를 내적 언어의 형태로 내 면화하는 능력의 결함에서 비롯된다고 주장하였다.

최근의 신경심리학적 증거도 이러한 이론적 제안을 뒷받 침하고 있다. 뇌의 언어적 정보처리는 자기통제에 관여하는 전두엽의 신경회로와 연계되어 있고(Pisoni et al., 2008), 언 어 특히, 행위(action)와 관련된 동사는 뇌의 운동 및 전운동 (premotor) 피질을 활성화시키는 등 언어체계와 운동체계도 서로 긴밀하게 연결되어있는 것으로 나타난다(van Elk, van Schie, Zwaan, \& Bekkering, 2010). 이러한 신경회로의 연계성 은 언어능력, 자기통제, 행동 문제 간의 밀접한 발달적 관계에 대한 생물학적 근거로 간주될 수 있다.

이러한 이론과 증거를 바탕으로, 최근 연구자들은 언어와 외현화 문제의 관계를 설명하는 가능한 기제 중 하나로 아동 의 자기통제력에 주목하고 있다(Lonigan et al., 2017; Petersen et al., 2013). 비록 자기통제의 구성개념에 대한 명확한 합의는 아직 이루어지지 못했지만, 넓은 의미에서 자기통제 혹은 자 기조절은 아동이 상황적 요구에 맞게 자신의 사고나 감정, 충 동을 통제하고 조절하는 능력을 포괄적으로 지칭한다는 데
에 대다수 연구자들은 동의한다(Bronson, 2000; McClelland \& Cameron, 2012). 개념의 광범위성과 발달적 중요성으로 인해 자기통제는 그동안 의도적 통제 기질이나 전두엽의 실행기능 과 같은 여러 유사 개념이나 용어로도 활발히 연구되었고, 그 결과 자기통제의 발달과정에 대해 많은 경험자료가 축적되었 다. 이 자료들은 공통적으로 유아기에 자기통제의 급속한 발 달이 이루어지며, 유아기 후반 나타나는 자기통제의 개인차는 이후 전 생애 동안 비교적 안정적이라는 것을 보여주었다.

기존의 경험자료에서 또한 주목할 점은 아동의 자기통제 가 언어 및 외현화 문제행동 둘 다와 관련되는 것으로 나타났 다는 것이다. 먼저, 언어와 자기통제의 관계는 앞서 기술된 이 론적 기반과 더불어 확고한 경험적 기반을 지닌다. 그동안 많 은 선행연구들이 유아기 어휘, 의사소통, 문해기술 등 다양한 언어적 기술들이 자기통제의 발달을 예측한다는 것을 보여주 었기 때문이다(Jacques \& Zelazo, 2005; McClelland et al., 2007; Roben, Cole, \& Armstrong, 2013; Son \& Choi, 2011). 더 나아 가, Vygotsky의 이론을 기초로 유아기 자기통제 향상에 미치 는 혼잣말 사용의 중재효과를 보여준 연구(Diamond, Barnett, Thomas, \& Munro, 2007)나, 유아기 언어발달이 실행기능 발 달을 선행한다는 것을 보여준 연구(Fuhs \& Day, 2011)는 모두 가 언어능력이 자기통제의 발달에서 핵심적 역할을 한다는 것 을 보여주었다고 할 수 있다.

자기통제와의 관계가 보고된 언어능력에는 어휘, 문해기술 을 비롯한 다양한 기술들이 있지만, 그중에도 수용어휘는 그 관계가 가장 일관되게 보고된 능력이라고 할 수 있다. 언어이 해력과 관련되는 수용어휘는 유아기 표현어휘나 읽기와 같은 다른 언어적 기술 발달의 주요 토대가 될 뿐 아니라, 일반 언 어지능에 대해서도 일관적으로 높은 상관을 나타내는 것으로 보고되어 있다(Carlson, Moses, \& Claxton, 2004; Y. Kim, Hong, Kim, Jang, \& Lee, 2009; Weiland, Barata, \& Yoshikawa, 2014). 이 러한 이유로 선행연구에서도 아동의 일반적 언어능력을 측 정하기 위한 단일 척도로 표준화된 수용어휘 척도가 사용되 곤 하였다(e.g., Carlson et al., 2004; Petersen et al., 2013). 그 예 로 Carlson과 Beck (2009)은 자기통제의 발달에서 내적 언어의 중요성을 강조하며, 수용어휘로 측정된 언어능력은 어린 아동 이 자기통제가 요구되는 상황에 적절히 대처하기 위해 자신과 의 대화(“나는 $X$ 를 하고 싶지만, 그러한 충동 $[X]$ 을 억제하고, 대신에 $\mathrm{Y}$ 를 해야 한다.")를 내면화하는 데에 필수적이라고 주 장하였다. 최근의 종단연구(Hughes, Ensor, Wilson, \& Graham, 2009)에서도 유아기 후반 실행기능 발달을 예측하는 여러 변 인 중에서 수용어휘로 측정된 언어능력이 가장 강력한 예측변 
인이라고 보고되었다.

다음으로, 자기통제와 외현화 문제의 관계에 대해서도 최 근 그 증거가 증가하고 있다. 선행연구들은 유아기와 학령 기 아동 모두에게서 이 둘의 관계를 보여주었으며(Hughes \& Ensor, 2011; S. Kim, 2014; Sulik et al., 2015), 특히 어릴 적부터 나타나는 외현화 문제일수록 자기통제적 결함과 더욱 밀접 히 관련된다는 것을 보여주었다(Calkins \& Keane, 2009). 자기 통제의 향상은 유아기 발달과업으로, 유아기 후반이 되면 아 동들은 대개 자신의 행동을 통제하는 일에 보다 숙달된다. 그 러나 그러한 향상이 이루어지지 못한 아동들은 이후에도 행 동 문제를 지속해서 보일 가능성이 크다. 그 예로, Eisenberg 등(2000)의 연구에서는 유아기에 주의조절력과 행동조절력 이 낮은 아동일수록 이후 학령기 전반에 걸쳐 보다 심각한 외 현화 문제를 보이는 것으로 나타났다. 최근 국내외의 메타분 석 연구(Chang \& Park, 2015; Schoemaker, Mulder, Deković, \& Matthys, 2013)도 유아기와 학령기 동안 다양한 개념과 지표를 사용하여 측정된 아동의 자기통제력이 외현화 문제의 발달과 관련된다는 것을 보여주었다.

이상의 선행연구 결과들은 모두 함께 아동의 언어, 자기통 제, 외현화 문제행동이 서로 밀접한 관계 속에서 발달해 나간 다는 것을 시사한다. 일반적으로 언어능력이 높은 아동들은 성인에 의해 제시되는 사회적 규칙과 그 합리적 이유, 문제해 결 책략 등을 보다 잘 이해하고 내면화할 수 있을 뿐 아니라 내 적 언어를 사용하여 자신의 부적절한 충동이나 생각, 감정을 더 잘 통제할 수 있을 것이며, 결국에는 보다 적응적인 발달을 이룰 수 있을 것이다.

그러나 이들 세 영역 간의 관계를 보다 정확히 살펴보기 위 해서는 아동의 성별을 고려할 필요가 있다. 언어, 자기통제, 외현화 문제행동은 모두 성별에 따른 차이가 비교적 일관되 게 보고된 영역들이기 때문이다. 유아기 남아들은 대체로 여 아들보다 평균적으로 언어능력이 낮고(Bornstein, Hahn, \& Haynes, 2004), 자기통제 수준도 낮은 것으로 보고되어 있다 (Else-Quest, Hyde, Goldsmith, \& Van Hulle, 2006). 외현화 문제 행동 영역에서도 남아의 성별이 그 발달적 위험을 높이는 주 된 위험요인으로 간주될 정도로, 남아는 여아에 비해 높은 수 준의 행동 문제를 보이는 경향이 강하다(Coie \& Dodge, 1998). 이로 인해 외현화 문제에서 남아가 지니는 발달적 취약성이 낮은 언어능력에서 비롯되거나(Brownlie et al., 2004), 혹은 낮 은 자기통제 수준에서 비롯될 수 있다고 제안되었다(Lonigan et al., 2017). 비록 이들 세 영역을 함께 고려한 관계에서의 성 차는 알려진 바가 제한적이지만, 외현화 문제에서 남아의 높
은 취약성이 언어적 지연과 자기통제적 결함 모두에 기인할 수 있다고 제안된 바 있다(Hay, 2007).

한편, 학령초기에는 외현화 문제행동 수준에서의 성차 가 더욱 뚜렷해지는데, 이는 유아기를 거치면서 외현화 문 제가 남아보다 여아에게서 더 큰 폭으로 감소하기 때문이다 (Keenan \& Shaw, 1997). 초등학교 1학년 시기는 아동이 학교 규칙의 준수, 교사 지시에 대한 순응, 또래와의 협력, 구조화 된 학습과제 수행 등 새로운 사회적, 학업적 도전에 직면하는 발달의 주요 전환기다. 이러한 시기에 외현화 문제가 자리 잡 으면, 아동은 많은 발달과업 달성에 어려움을 겪게 되고, 결국 부적응적 문제가 장기화될 위험이 크게 증가한다(Campbell et al., 2010). 따라서 학령기 외현화 문제행동 발달을 예방하고 적응적 발달을 돕기 위해서는 언어나 자기통제와 같이 가정이 나 학교에서 조기 중재가 비교적 용이하게 이루어질 수 있는 초기 요인에 대한 이해가 필수적이다.

모두 종합하면, 유아기 언어능력이 어떻게 학령기 외현화 문제에까지 그 종단적 영향력을 행사할 수 있는지 이해하기 위해서는 아동의 자기통제와 성별을 모두 함께 고려할 필요가 있어 보인다. 특히 언어와 자기통제의 관계에 대한 확고한 이 론적, 경험적 기반에 근거하면, 초기 언어가 이후 외현화 문제 에 영향을 미치는 기제는 자기통제를 통해 설명될 수 있을 것 으로 가정해 볼 수 있다. 아마도 어린 아동의 언어능력은 유아 기 후반에 안정화되기 시작하는 자기통제의 개인차를 낳을 것 이고, 이러한 자기통제의 개인차는 이후 외현화 문제에서의 개인차를 낳을 것이다. 또한, 이러한 경로는 여아에 비해 외현 화 문제의 발달에서 보다 취약하다고 알려진 남아에게서 더욱 강하게 나타날 것이다.

그러나 이러한 추론에는 몇 가지 제한이 따르는데, 그 이유 는 지금까지 학령기 외현화 문제를 예측하는 유아기 변인들을 살펴봄에 있어 언어와 자기통제를 함께 고려한 연구도 제한적 이지만, 이들 변인 간 관계의 본질이 무엇인지 살펴본 연구는 더욱 제한적이기 때문이다(Lonigan et al., 2017). 또한, 성차와 관련해서도 각 변인에서의 성차만 주로 많이 보고되었고, 변 인 간 관계에서의 성차는 보고된 바가 많지 않다. 특히 세 변인 의 관계에서 성차를 살펴본 경우는 더욱 드물다. 그나마 일부 선행연구에서 이들 세 변인을 함께 고려하여 성차를 살펴보 았으나 연구가설에도 불구하고 성차가 발견되지 않는 등(e.g., Campbell et al., 2010) 그 결과가 다소 명확하지 않다.

이러한 필요성에 따라, 본 연구의 목적은 5세에서 7세 사이 에 초기의 언어능력과 자기통제, 그리고 이후의 외현화 문제 행동 간의 종단적 관계가 아동 성별에 따라 어떻게 나타나는 
지 살펴보는 데에 있다. 기존의 이론과 경험자료를 토대로, 유 아기 언어능력이 자기통제를 매개로 초등학교 1학년 외현화 문제행동에 영향을 미칠 것으로 가정하였으며, 이러한 경로는 외현화 문제의 발달에서 보다 취약하다고 알려진 남아에게서 더 강하게 나타날 것으로 가정하였다. 각 변인에 대한 지표로 는, 언어능력의 경우 유아기 아동의 일반적 언어능력에 대한 단일 지표로 종종 사용되는 수용어휘력을, 자기통제는 아동이 가정과 학교를 포함한 일상적인 사회적 맥락에서 자신의 충동 이나 감정을 통제하는 것과 관련된 자기통제 지표를 사용하였 다. 그리고 외현화 문제행동은 아동의 행동 적응에 대한 가장 포괄적 지표 중 하나인 전반적(overall) 외현화 문제행동을 사 용하였다. 본 연구의 연구문제는 다음과 같다.

\section{연구문제 1}

아동 성별에 따라 5 세의 언어능력, 6 세의 자기통제, 7 세의 외 현화 문제행동 각각의 수준에서 차이가 있는가?

\section{연구문제 2}

아동 성별에 따라 5 세의 언어능력, 6 세의 자기통제, 7 세의 외 현화 문제행동 간의 종단적 관계에서 차이가 있는가?

\section{연구문제 3}

아동 성별에 따라 5 세 언어능력이 6 세의 자기통제를 매개로 하여 7 세 외현화 문제행동에 미치는 종단적 영향에는 차이가 있는가?

\section{Methods}

\section{연구대상}

본 연구는 육아정책연구소 한국아동패널(Panel Study on Korean Children [PSKC])의 6차년도(2013년), 7차년도(2014년), 8 차년도(2015년) 자료를 사용하였다. 한국아동패널은 2008년 에 신생아를 출생한 2,150 가구를 전체 표본으로 구축하여, 이 후 매해 아동발달, 가족과 지역사회 환경 등을 조사한 자료를 제공하고 있다. 분석에 사용된 연구대상은 모든 연구변인에 응 답한 1,102 가구의 자료였다. 6차년도 7차년도 조사에서 아동 은 각각 5세(시기 1)와 6세(시기 2)로 취학 전이었고, 8차년도 조사에서는 7세(시기 3)로 초등학교 1학년이었다. 연구대상 남 아는 569명(51.6\%), 여아는 533명(48.4\%)으로 그 분포가 유사 하였다. 아동의 평균 월령은 시기 1 을 기준으로 남아 62.59 개월
$(S D=1.30)$, 여아 62.59 개월 $(S D=1.43)$ 로 거의 동일하였다. 부 모 학력과 가구소득도 남아와 여아에게서 그 분포가 서로 유 사하였다. 남아의 경우 부 학력이 대졸 385명(67.7\%), 고졸 141 명(24.8\%), 대학원졸 41 명(7.2\%), 중졸 2 명 $(0.4 \%)$ 순으로, 모 학력이 대졸 388 명 $(68.0 \%)$, 고졸 160 명 $(28.1 \%)$, 대학원졸 20 명(3.5\%), 중졸 1 명 $(0.2 \%)$ 순으로 많았다. 여아의 경우도 부 학 력이 대졸 316명(59.3\%), 고졸 154 명(28.9\%), 대학원졸 61명 (11.4\%), 중졸 2명 $(0.4 \%)$ 순으로, 모 학력이 대졸 337명(63.2\%), 고졸 160명(30.0\%), 대학원졸 32명(6.0\%), 중졸 4명(0.8\%) 순으 로 많았다. 월평균 가구소득(단위: 만원)도 Table 1에 제시되었 듯이, 남아 $(M=419.93, S D=172.68)$ 와 여아 $(M=435.79, S D=$ 198.14)에게서 서로 유사하였다.

\section{연구도구}

$$
\text { 언어능력 }
$$

5세(시기 1)의 언어능력은 한국아동패널 6차년도 조사에서 표 준화 검사인 수용 - 표현 어휘력 검사(Receptive and Expressive Vocabulary Test [REVT]; Y. Kim et al., 2009)의 수용어휘력검사 (Receptive Expressive Vocabulary Test-Receptive [REVT-R])를 사용 하여 측정되었다. REVT-R은 타인의 말을 듣고 이해하는 것과 관련된 언어능력을 평가하는 검사로, 만 2 세 아동부터 16 세 이 상 성인의 수용어휘력을 측정하도록 제작되었다. 이 척도는 외 국의 Peabody Picture Vocabulary Test-Revised (PPVT-R; Dunn \& Dunn, 1981)을 기초로 국내에서 표준화된 그림어휘력검사(Y. Kim, Jang, Lim, \& Baek, 1995)와 .90이 넘는 높은 상관이 보고되 어 있다. REVT-R (총 185 문항)은 아동이 4 개의 보기 그림 중에 서 검사자가 들려준 어휘에 해당하는 그림을 손으로 가리키는 방식으로 검사가 진행된다. 검사 후반으로 갈수록 제시되는 어 휘 난이도가 높아지며, 아동이 연속된 8개 문항 중 6 개 이상 틀 리면 검사가 종료된다. 각 문항에서 정반응은 1 점, 오반응은 0 점으로 채점된다. 검사의 원점수가 분석에 사용되었으며, 점수 가 높을수록 아동의 수용어휘력이 높다는 것을 의미한다.

\section{자기통제}

6세(시기 2)의 자기통제는 한국아동패널 7차년도 조사에서 취학전 아동용 사회적 기술 척도(K-Social Skills Ratings System [K-SSRS]; Suh, 2004)를 패널 연구진이 예비조사를 거쳐 검토 . 수정한 것을 사용하여 측정되었다. K-SSRS은 Gresham과 Elliot 
(1990)이 미국에서 표준화한 Social Skills Ratings System (SSRS) 을 국내에서 타당화한 것으로, 취학 전 아동의 사회적 기술을 측정하는 척도다. K-SSRS은 부모평정용과 교사평정용이 있는 데, 부모평정 척도(총 32 문항)는 주장성, 협력성, 자기통제, 책 임성의 4 개 하위척도로, 교사평정 척도(총 21 문항)는 주장성, 협력성, 자기통제의 3 개 하위척도로 구성된다. 본 연구는 이중 부모평정 자기통제 척도(7문항)와 교사평정 자기통제 척도(7 문항)를 둘 다 사용하였다. 이는 척도가 가정과 학교 모두에서 평가되어야 보다 포괄적이고 신뢰로운 측정치를 제공할 수 있 다는 제안에 따른 것이다(Suh, 2004). Wright와 Beaver (2005)도 SSRS의 부모평정 자기통제 척도가 사회적 맥락에서 아동의 자 기통제를 측정하는 신뢰로운 척도로 널리 사용되고는 있으나, 교사평정 자료에 비해 신뢰도가 다소 낮고, 가정 밖 행동은 포 착하지 못한다는 한계가 있으므로 부모평정과 교사평정을 함 께 사용하는 것이 적절하다고 주장하였다. K-SSRS의 자기통제 척도는 유아가 사회적 상황에서 자신의 부적절한 충동과 감정 을 통제하는지, 규칙과 질서를 지키는지 등을 평가한다. 부모 평정 척도는 가정 및 일상생활 맥락과 관련된 문항들로 구성되 며(예: “부모의 지시에 따른다.”), 교사평정 척도는 학교 맥락과 관련된 문항들로 구성된다(예: “또래와의 갈등상황에서 자신 의 감정을 조절한다.”). 각 문항은 전혀 아니다(1점)에서 매우 자주 그렇다(3점)의 3점 척도로 평가하게 되어 있다. 본 연구에 서 척도 신뢰도(Cronbach's $\alpha$ )는 부모평정용이 .80 , 교사평정용 이 .84이었다. 단일변인 구성을 위해 두 척도 간 상관분석을 실 시한 결과, 상관이 통계적으로 매우 유의한 것으로 나타났으 므로 $(r=.20, p<.001)$, 교사평정과 부모평정 점수를 합한 후 그 평균값을 사용하여 자기통제 단일변인을 구성하였다.

\section{외현화 문제행동}

초등학교 1학년(7세, 시기 3) 외현화 문제행동은 한국아동 패널 8차년도 조사에서 아동.청소년행동평가척도(Child Behavior Checklist for ages 6-18 [CBCL 6-18])를 사용하여 측정 되었다. CBCL 6-18은 Achenbach와 Rescola (2001)가 개발한 척 도를 $\mathrm{Oh}$ 와 $\mathrm{Kim}$ (2010)이 한국판으로 표준화한 것으로, 6-18 세 아동과 청소년을 대상으로 부모가 평정하는 척도다. $\mathrm{CBCL}$ 6-18 (전체 120 문항)은 외현화 문제행동 척도, 내재화 문제행 동 척도, 그리고 총 문제행동 척도로 구성된다. 이중 본 연구 는 외현화 문제행동 척도를 사용하였다. 외현화 문제행동 척 도(총 35 문항)는 사회적으로 부적절한 행동이 겉으로 뚜렷이 드러나는 문제행동을 평가하는 문항들로 이루어져 있다. 외현
화 문제행동 척도는 그 하위척도인 공격행동 척도와 규칙위 반 척도의 총점으로 계산되므로, 두 하위척도와의 구별을 위 해 전반적(overall) 외현화 문제행동 척도로도 불린다. 문항 예 로는, “싸움을 많이 한다.” 등이 있다. 각 문항은 전혀 해당되 지 않는다(0점)에서 자주 그런 일이 있거나 많이 그렇다(2점) 의 3점 척도로 평가하게 되어 있다. 척도의 원점수가 분석에 사용되었고, 점수가 높을수록 외현화 문제행동의 수준이 높다 는 것을 의미한다. 본 연구에서 외현화 문제행동 척도 신뢰도 (Cronbach's $\alpha$ )는 .86이었다.

\section{통제변인}

통제변인으로 시기 1 의 부 학력, 모 학력, 가구소득 세 변인이 포함되었다. 이 변인들은 선행연구(e.g., Choi, Choi, \& Nam, 2013; Petersen et al., 2013; Sulik et al., 2015)에서 언어, 자기통 제, 외현화 문제행동 모두와의 밀접한 관련성이 보고된 변인 들로, 본 연구의 예측변인과 종속변인의 관계에 또 다른 영향 력을 미칠 가능성이 크기 때문에 그 영향을 통제할 필요가 있 는 변인들이다. 부 학력 $(M d n=6$ [4년제 대학졸업])과 모 학력 $(M d n=5$ [전문대학졸업])은 둘 다 각각 무학력(1점)부터 대학 원졸업(9점)의 9개 범주로 변인을 구성하였다. 가구소득 변인 은 가구 월평균 소득의 합계(단위: 만원)를 사용하였다.

\section{자료분석}

연구문제를 살펴보기 위한 자료분석은 다음 순서로 이루어졌 다. 먼저, 모든 연구변인의 평균과 표준편차를 아동 성별에 따 라 제시하고, 주요 변인에서의 성차를 살펴보기 위해(연구문 제 1) 전체 아동을 대상으로 성별에 따른 변인의 평균차 검증 을 실시하였다. 다음으로, 성별에 따른 변인 관계와 매개효과 를 검증하기 위해(연구문제 2와 3) 남녀 아동별로 상관분석과 위계적 회귀분석을 실시하고 그 결과를 서로 비교하였다. 통 계분석에는 SPSS 21.0 (IBM Co., Armonk, NY)을 사용하였다.

\section{Results}

\section{성별에 따른 유아기 언어능력 및 자기통제와 초등학교 1학년 외현화 문제행동 수준에서의 평균 차이}


Table 1

Means and Standard Deviations of All Variables by Child's Gender

\begin{tabular}{|c|c|c|c|c|c|}
\hline \multirow[b]{2}{*}{ Variables } & \multicolumn{2}{|c|}{ Boys $(n=569)$} & \multicolumn{2}{|c|}{ Girls $(n=533)$} & \multirow[b]{2}{*}{ Gender difference } \\
\hline & $M$ & $S D$ & $M$ & $S D$ & \\
\hline \multicolumn{6}{|l|}{ Time 1} \\
\hline Paternal education & 5.48 & 1.28 & 5.57 & 1.49 & ns \\
\hline Maternal education & 5.25 & 1.09 & 5.30 & 1.26 & ns \\
\hline Family income & 419.93 & 172.68 & 435.79 & 198.14 & $n s$ \\
\hline Language ability & 58.21 & 9.89 & 60.48 & 8.73 & Girls $>$ Boys, $p<.001$ \\
\hline \multicolumn{6}{|l|}{ Time 2} \\
\hline Self-control & 16.85 & 2.19 & 17.70 & 2.04 & Girls $>$ Boys, $p<.001$ \\
\hline \multicolumn{6}{|l|}{ Time 3} \\
\hline EXT behavior problems & 4.61 & 4.33 & 3.74 & 4.26 & Boys $>$ Girls, $p<.001$ \\
\hline
\end{tabular}

Note. EXT = externalizing; $n s=$ nonsignificant.

Table 2

Zero-Order Correlations Between All Variables for Boys and Girls

\begin{tabular}{|c|c|c|c|c|c|c|}
\hline & 1 & 2 & 3 & 4 & 5 & 6 \\
\hline \multicolumn{7}{|l|}{ Time 1} \\
\hline 1. Paternal education & - & $.55^{* * *}$ & $.29^{* * *}$ & $.11^{* *}$ & .08 & -.06 \\
\hline 3. Family income & $.23^{* * *}$ & $.29^{* * *}$ & - & .08 & .01 & -.04 \\
\hline 4. Language ability & $.17^{* * *}$ & $.12^{* *}$ & $.09^{*}$ & - & $.19^{* * *}$ & -.07 \\
\hline 5. Self-control & $.14^{* *}$ & .07 & .04 & $.19^{* * *}$ & - & $-.26^{* * *}$ \\
\hline \multicolumn{7}{|l|}{ Time 3} \\
\hline 6. EXT behavior problems & $-.14^{* *}$ & $-.12^{* *}$ & -.02 & $-.14^{* *}$ & $-.35^{* * *}$ & - \\
\hline
\end{tabular}

Note. Boys' $n=569$; Girls' $n=533$; EXT = externalizing.

Values below the diagonal reflect boys, whereas values above the diagonal reflect girls.

${ }^{*} p<.05 .{ }^{* *} p<.01 .{ }^{* * *} p<.001$.

Table 1에는 아동 성별에 따른 모든 변인의 평균 및 표준편차 와 함께, 각 변인의 평균에 대한 성차 분석결과가 제시되어 있 다. 연구문제 1 (성별에 따른 언어능력, 자기통제, 외현화 문제 행동 수준에서의 차이)을 살펴보기 위해 $t$-검정을 실시한 결 과, 세 변인 각각에서 모두 성차가 유의한 것으로 나타났다. 즉, 남아들은 여아들에 비해 시기 1 에 언어능력 평균 $(t=-4.06$, $p<.001)$ 과 시기 2 에 자기통제 평균 $(t=-6.63, p<.001)$ 이 모두 낮았고, 시기 3 에는 외현화 문제행동 평균이 높았다 $(t=3.37, p$ <.001). 통제변인에서의 성차는 모두 유의하지 않았다.

성별에 따른 유아기 언어능력 및 자기통제와 초등학교 1학년 외현화 문제행동 간의 상관관계
Table 2에는 연구문제 2(성별에 따른 언어능력, 자기통제, 외 현화 문제행동 간의 종단적 관계)와 관련하여 남녀 아동별로 상관분석을 실시한 결과가 제시되어 있다. 주요 연구변인을 중심으로 살펴보면, 먼저 남아들의 경우 언어, 자기통제, 외현 화 문제행동 간 상관이 모두 유의하였다. 즉, 남아들은 시기 1 에 언어능력이 낮을수록, 시기 2에는 자기통제 수준이 낮았고 $(r=.19, p<.001)$ 시기 3 에는 외현화 문제행동 수준이 높았다 $(r=-.14, p<.01)$. 또한, 시기 2에 자기통제 수준이 낮을수록 시 기 3 에 외현화 문제행동 수준이 높았다 $(r=-.35, p<.001)$.

다음 여아들의 경우에는 언어능력과 자기통제의 상관과 자 기통제와 외현화 문제행동의 상관만이 유의했다. 즉, 여아들 은 시기 1 에 언어능력이 낮을수록 시기 2에 자기통제 수준이 낮았고 $(r=.19, p<.001)$, 시기 2에 자기통제 수준이 낮을수록 
Table 3

Summary of Hierarchical Regression Analyses to Test the Mediating Role of T2 Self-Control in Predicting T3 Externalizing Behaviors from T1 Language Ability for the Boys

\begin{tabular}{llllrr}
\hline \multicolumn{1}{c}{ Step } & \multicolumn{1}{c}{ Dependent variable } & \multicolumn{1}{c}{ Predictors } & $\beta$ & $R^{2}$ & \multicolumn{1}{c}{$F$} \\
\hline 1 & EXT behavior problems (T3) & Language ability (T1) & $-.12^{* *}$ & .04 & $5.21^{* * *}$ \\
2 & Self-control (T2) & Language ability (T1) & $.18^{* * *}$ & .05 & $7.52^{* * *}$ \\
3 & EXT behavior problems (T3) & Language ability (T1) & -.06 & .14 & $17.77^{* * *}$ \\
& & Self-control (T2) & $-.33^{* * *}$ & & \\
\hline
\end{tabular}

Note. Boys' $n=569$.

Paternal education, maternal education, and family income at Time 1 were included as covariates in all analyses.

${ }^{* *} p<.01 .{ }^{* * *} p<.001$.

시기 3에 외현화 문제행동 수준이 높았다 $(r=-26, p<.001)$. 그 러나 시기 1 언어능력과 시기 3 외현화 문제행동의 상관은 유 의하지 않았다.

남아와 여아의 결과를 비교하면, 남아들은 모든 주요 변인 의 상관이 유의했으나, 여아들은 언어능력(시기 1)과 외현화 문제행동(시기 3)의 상관을 제외한 나머지 상관만이 유의했 다. 보다 구체적으로, 언어능력과 외현화 문제의 상관은 남아 들에게서만 유의했고 여아들에게서는 유의하지 않았으며, 자 기통제와 외현화 문제의 상관도 여아들보다 남아들에게서 좀 더 강했다. 한편, 언어능력과 자기통제의 상관은 남아와 여아 모두에게서 매우 유의하게 나타났다. 이러한 상관분석 결과는 아동 성별에 따라 변인의 관계 패턴이 다르다는 것을 보여줌 과 동시에, 이후의 매개효과 검증을 위한 상관의 기본 조건이 남아에게서만 충족되었다는 것을 의미한다.

\section{성별에 따른 유아기 언어능력과 초등학교 1 학년 외현화 문제행동의 관계에서 자기통제 의 매개효과}

앞선 상관분석 결과에서 여아의 경우 언어능력과 외현화 문제 행동의 상관이 유의하지 않았으므로, 연구문제 3 과 관련한 매 개효과 검증은 주요 변인 간 상관이 모두 유의했던 남아를 대 상으로만 실시하였다. 매개효과 검증은 Baron과 Kenny (1986) 가 제안한 방식에 따른 세 단계 회귀분석을 통해 이루어졌다. 이 방식에서는, 1) 예측변인이 종속변인에 유의한 영향을 미 치고, 2) 예측변인이 매개변인에 유의한 영향을 미치며, 3) 예 측변인과 매개변인을 동시에 회귀식에 투입했을 때 매개변 인은 종속변인에 유의한 영향을 미치지만, 매개변인의 추가 로 인해 예측변인의 종속변인에 대한 영향력이 더 이상 유의 하지 않거나(완전매개), 또는 실질적으로 감소해야(부분매개)
그 매개효과가 유의한 것으로 본다. 모든 회귀분석에서는 그 영향력을 통제하기 위해 통제변인인 부 학력, 모 학력, 가구소 득을 제일 먼저 한 블록으로 함께 투입하였는데, 이들 통제변 인의 설명력 합은 회귀분석마다 모두 유의한 것으로 나타났다 (all $p s<.01$ ).

Table 3에 요약되어 있듯이, 첫 번째 분석단계에서 남아의 언어능력(예측변인, 시기 1)은 외현화 문제행동(종속변인, 시 기 3)에 유의한 영향을 미쳤다 $(\beta=-.12, p<.01)$. 두 번째 분석 단계에서, 언어능력은 자기통제(매개변인, 시기 2)에도 유의 한 영향을 미쳤다 $(\beta=.18, p<.001)$. 마지막 세 번째 분석단계 에서, 언어능력과 자기통제를 동시에 회귀식에 투입하자 종속 변인에 대한 자기통제의 예측력은 매우 유의했으나 $(\beta=-.33$, $p<.001)$, 언어능력의 예측력은 유의하지 않은 것으로 나타닜 다. 즉, 자기통제의 추가로 인해 종속변인에 대한 언어능력의 표준화 회귀계수( $\beta$ )가 -.12 ( $p<.01$, step 1)에서 -.06 (ns, step 3) 으로 크게 줄어들어 그 예측력이 더이상 유의하지 않게 된 것 이다. 여기서 자기통제는 완전 매개효과를 지닌다고 해석할

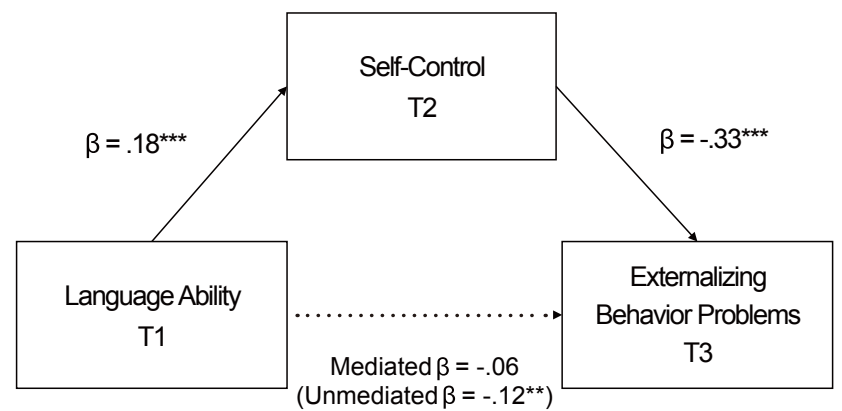

Figure 1. Boys' self-control fully mediates the relation between language ability and externalizing behavior problems. Paternal education, maternal education, and family income at Time 1 were controlled for in all analyses.

${ }^{* *} p<.01 .{ }^{* * *} p<.001$. 
수 있다. 세 번째 분석단계에서, 통제변인, 언어능력, 자기통제 는 모두 함께 종속변인 변량의 $14 \%$ 를 설명하였다 $(F(5,563)=$ $17.77, p<.001)$. 추가적으로, 이러한 자기통제의 완전 매개효 과가 유의한지 검증하기 위해 sobel test를 실시한 결과, $z$ 값이 $-3.72(p<.001)$ 로 나타나 그 매개효과가 유의한 것으로 나타 났다. Figure 1은 이상의 분석결과를 토대로 남아에게 나타난 자기통제의 매개효과를 도식화한 것이다.

\section{Discussion}

이론적으로 어린 아동의 언어능력은 적응적인 행동 발달의 근간을 이루는 자기통제력의 주요 도구로 간주된다(Barkley, 1997; Fernyhough, 2010). 본 연구는 이러한 제안과 기존의 경 험자료를 토대로 유아기의 언어능력이 자기통제를 매개로 초 등학교 1학년 외현화 문제행동에 그 종단적 영향을 미치는지 검증하고자 하였다. 그리고 더 나아가 이러한 경로에서 아동 의 성별에 따른 차이가 존재하는지 확인하고자 하였다. 연구 결과를 연구문제 순서에 따라 논의하면 다음과 같다.

연구문제 1 과 관련하여, 유아기의 언어능력 및 자기통제와 초등학교 1학년 외현화 문제행동 수준에서 성별에 따른 차이 를 살펴본 결과는 이들 세 영역 모두에서 성차가 존재한다는 것을 확인시켜 주었다. 남아들은 대체로 여아들에 비해 5세에 언어능력이 낮았고, 6 세에는 자기통제 수준도 낮았으며, 초등 학교 1학년인 7세에는 외현화 문제행동 수준이 높은 것으로 나타났다. 이러한 결과는 그동안 많은 선행연구에서 보고된, 유아기 언어능력에서의 성차(e.g., Bornstein et al., 2004)와 자 기통제력에서의 성차(e.g., Else-Quest et al., 2006), 그리고 학령 기 외현화 문제행동 수준에서의 성차(e.g., Bongers, Koot, van der Ende, \& Verhulst, 2003; Seo, 2011)와 모두 일치하는 결과다.

연구문제 2 즉, 유아기 언어능력과 자기통제, 그리고 초등 학교 1학년 외현화 문제행동 간의 종단적 관계가 남아와 여 아에게서 서로 다르게 나타나는지 살펴본 결과는, 성별에 따 라 그 관계 패턴이 서로 다르다는 것을 보여주었다. 남아들에 게 있어 초등학교 1 학년 외현화 문제행동에 대해 5 세의 언어 능력 및 6 세의 자기통제 각각이 지니는 상관의 정도는 여아들 에게서 나타난 상관보다 모두 더 강했다. 특히 언어능력과 외 현화 문제행동의 상관은 오직 남아들에게서만 유의한 것으로 나타났다. 이러한 결과는 유아기 언어와 학령기 외현화 문제 의 종단적 관계에서 보고되었던 성차(e.g., Baker \& Cantwell, 1982; Brownlie et al., 2004; Petersen et al., 2013)나, 유아기 자기
통제와 학령기 외현화 문제의 관계에서 보고되었던 성차(e.g., Lonigan et al., 2017)와 일관된 결과로 볼 수 있다.

연구문제 2 의 분석결과에 따라, 마지막 연구문제 3 에 대해 서는 남아들만을 대상으로 매개효과 검증이 이루어졌다. 그 결과는 모든 검증단계에서 부모 학력과 가구소득의 영향을 통 제한 후에도, 5 세 언어능력과 7세 외현화 문제행동의 관계를 6 세 자기통제가 완전 매개한다는 것을 보여주었다. 이는 곧 남 아들의 학령초기 외현화 문제를 예측함에 있어 유아기 언어능 력은 자기통제를 통해서만 그 종단적 영향력을 행사할 수 있 었다는 것을 의미한다. 따라서 초기 언어와 이후 행동 문제의 관계가 자기통제 발달을 통해 설명될 수 있다는 기존의 제안 (Barkley, 1997; Fernyhough, 2010)은 이 시기 남아들을 대상으 로 지지되었다고 할 수 있다.

가정된 매개모형에서 나타난 성차와 관련해서는 이들 세 변인과 성별을 함께 고려한 선행연구가 제한적인 데다가 연구 에 사용된 척도도 서로 달라 그 결과를 직접 비교하기에는 다 소 어려움이 있다. 다만 본 연구결과는 Campbell 등(2010)의 연구에서 성별과 무관하게 언어 및 자기통제 둘 다 외현화 문 제에 대한 예측력을 나타내지 못한 것과는 다른 결과라고 할 수 있다. 비록 Campbell 등의 연구가 매개효과를 가정한 것은 아니었으나, 변인 관계에서 성차를 가정했음에도 성차가 검증 되지 못한 것이다. 이에 대해 연구자들은 사용된 언어 척도(표 현언어와 언어이해력의 총합)나 자기통제 척도(만족지연 과 제수행)가 남녀 아동 모두에게 그 종단적 관계를 포착하기에 적절치 않았을 수 있다고 논의하였다. 아마도 본 연구에서 비 교적 뚜렷이 나타난 성차가 Campbell 등의 연구에서 나타나지 않은 이유가 연구자들의 논의처럼 척도나 지표 특성에 기인한 것일 수도 있을 것이다. 그러나 관련 선행연구가 매우 부족한 상황에서 이러한 제한적인 비교보다는 좀 더 넓은 맥락에서의 해석이 적절할 것으로 보인다.

그동안 유아기나 학령기 아동들에게 있어 언어, 자기통제, 외현화 문제행동 영역마다 대체로 일관된 성차가 보고되어왔 고, 보다 최근에는 외현화 문제에 대한 언어 또는 자기통제 각 각의 관계에서도 그 부적 관계의 정도가 대체로 남아에게 더 강한 것으로 보고되고 있다(e.g., Bongers et al., 2003; Brownlie et al., 2004). 이러한 일관된 성차 패턴은 본 연구에서 나타난 것과도 일치한다. 따라서 Hay (2007)의 주장처럼, 외현화 문제 행동의 발달에서 남아가 지니는 취약성이 남아의 또 다른 내 적 취약성인, 언어적 지연과 자기통제력 부족 모두로부터 비 롯된다고 가정할만한 충분한 경험적 근거가 있다고 할 수 있 다. 본 연구의 결과는 이러한 제안을 실질적으로 뒷받침하는 
증거를 제공했다고 할 수 있을 것이다.

한편, 본 연구에서 가정된 종단적 매개모형이 남아에게만 유의하고 여아에게서는 검증되지 못한 것은 여아의 경우 검증 의 전제조건 중 하나인 언어능력(예측변인)과 외현화 문제행 동(종속변인)의 관계 자체가 유의하지 않았기 때문이다. 이는 Brownlie 등(2004)의 종단연구에서 오직 남아들의 경우에만 5 세의 언어적 결함이 이후의 외현화 문제와 관련된다고 보고 된 것과 유사하다고 할 수 있겠다. 그러나 비록 그 정도가 남아 보다 약할지라도 여아에게서도 매개효과를 기대할 만한 근거 가 있음에도 불구하고 그 효과가 검증되지 못한 것은 연구대 상 아동들의 연령시기와도 관련이 있을 수 있다. 즉, 시기적으 로 5세와 7세는 각각 언어능력과 외현화 문제에서 성차가 크 게 두드러지는 시기인 데다가, 두 변인 간에 존재하는 2 년이라 는 시간적 거리도 다른 변인에 비해 멀었기 때문에 그 종단적 관계가 포착되기 더욱 어려웠을 수 있다. 그러나 현재로선 관 련 근거가 부족하므로, 이러한 가능성은 후속연구에서 실증적 으로 검토되어야 할 것이다.

요약하면, 연구결과는 초등학교 1학년 남아들의 외현화 문 제행동에 대해 유아기 언어적 지연이 미치는 종단적 영향이 자기통제의 부족으로 설명될 수 있다는 것을 보여주었다. 이 러한 자기통제의 매개효과는 외현화 문제에 대한 부모 학력과 가구소득의 영향력을 모두 통제한 후에도 여전히 유의하게 나 타났다는 점에서 더욱 의미가 있다. 남아들은 대체로 여아들 에 비해 유아기에 언어능력과 자기통제 수준이 모두 낮았고, 초등학교 1학년에 외현화 문제행동 수준은 높았다. 이에 따라 유아기 언어능력과 자기통제가 각각 이후의 외현화 문제와 부 적으로 관계되는 정도도 남아들에게서 현저히 강했고, 결과적 으로 자기통제의 매개효과도 남아들에게서만 검증될 수 있었 던 것으로 보인다. 결론적으로, 유아기 언어적 지연이 이후의 자기통제 발달을 저해하고, 이는 결국 외현화 문제를 증가시 킬 것이라는 가정은 남아들에게서 보다 확고히 지지되었다고 할 수 있다.

이러한 결과가 지니는 의의는 첫째, 학령전환기 외현화 문 제행동에 대한 유아기 언어능력의 종단적 영향을 살펴봄에 있어 전국규모의 패널 자료를 통해 그동안 주로 간접적으로 추론되었던 자기통제의 잠재적 매개역할(e.g., Barkley, 1997; Petersen et al., 2013)에 대한 보다 직접적인 증거를 제공했다는 것이다. 둘째, 이 시기 언어, 자기통제, 외현화 문제행동으로 이어지는 발달경로가 여아들에 비해 남아들에게서 현저히 강 하다는 것을 보여줌으로써 기존의 경험자료를 확장했다는 것 이다.
본 연구의 결과는 학령기 외현화 문제행동을 예방하기 위 해서는 유아기 아동들에게 언어와 자기통제 모두를 목표로 하 는 중재가 효과적일 수 있다는 것과, 그러한 중재가 남아들을 대상으로 더욱 적극적으로 이루어질 필요가 있다는 것을 시사 한다. 아동기에 나타나는 외현화 문제행동은 청소년기부터 나 타나는 문제보다 오래 지속되는 경향이 강하고, 이후의 발달 과정에서 외현화 문제행동을 포함하여 비행, 학업실패, 반사 회적 행동 등과 같은 다양한 부정적 발달결과를 야기할 위험 성도 크다고 알려져 있다(Broidy et al., 2003; Campbell, 2002). 그러나 이와 동시에, 아동기 특히, 유아기는 언어와 자기통제 의 발달이 모두 빠르게 이루어지는 시기로, 환경 자극의 영향 에 민감하기 때문에 그만큼 변화가능성도 크다고 알려져 있 다(Blair \& Diamond, 2008). 최근에 유아기 아동들의 언어능력 과 자기통제 향상을 목표로 하는 교육적 중재나 훈련이 단기 적 효과를 넘어 중장기적 효과가 증명되었다는 사실(Blair \& Raver, 2014; Diamond et al., 2007)은 고무적이라 할 수 있다.

마지막으로 본 연구의 한계점을 밝히고 후속연구를 위해 제언하면 다음과 같다. 첫째, 본 연구는 변인 관계를 살펴봄에 있어 주로 단일 척도로 구성된 변인을 사용했다는 한계를 지 닌다. 비록 이들 척도가 선행연구를 참고한 것이지만, 단일 척 도만으로 각 변인이 지니는 모든 측면을 포착할 수는 없을 것 이다. 언어와 자기통제는 둘 다 광범위한 변인이므로, 후속연 구에서 각 변인을 충분히 나타내기 위해서는 다양하고 종합적 인 척도의 구성을 고려할 필요가 있다. 특히 언어의 경우, 이 론적으로 자기통제적 기능을 지닌다고 가정되는 아동의 내적 언어는 수용언어뿐 아니라 표현언어와도 관련된다(e.g., Fuhs $\&$ Day, 2011). 따라서 이 둘을 함께 살펴보는 것은 언어의 어 느 측면이 자기통제와 외현화 문제로 이어지는 관계를 보다 잘 설명할 수 있는지 비교할 수 있게 해줄 것이다. 둘째, 본 연 구는 종단분석에서 특정 시점에서의 자료만 고려했기에 변인 관계의 방향성이나 변화량에 대한 결론은 명확지 못하다는 한 계를 지닌다. 후속연구에서는 다시점에서 반복 측정한 자료를 활용한 종단연구설계를 통해 변인 간 관계에 대한 더욱 풍부 한 정보를 제공할 수 있을 것이다.

\section{Conflict of Interest}

No potential conflict of interest relevant to this article was reported. 


\section{References}

\section{In English}

Baker, L., \& Cantwell, D. P. (1982). Developmental, social and behavioral characteristics of speech and language disordered children. Child Psychiatry and Human Development, 12(4), 195-206. doi:10.1007/BF01812585

Barkley, R. A. (1997). ADHD and the nature of self-control. New York: The Guilford Press.

Baron, R. M., \& Kenny, D. A. (1986). The moderator-mediator variable distinction in social psychological research: Conceptual, strategic, and statistical considerations. Journal of Personality and Social Psychology, 51(6), 1173-1182. doi:10.1037/0022-3514.51.6.1173

Beitchman, J. H., Wilson, B., Johnson, C. J., Atkinson, L., Young, A., Adlaf, E., . . . Douglas, L. (2001). Fourteen-year follow-up of speech/language-impaired and control children: Psychiatric outcome. Journal of the American Academy of Child \& Adolescent Psychiatry, 40(1), 75-82. doi:10.1097/00004583200101000-00019

Blair, C., \& Diamond, A. (2008). Biological processes in prevention and intervention: The promotion of self-regulation as a means of preventing school failure. Development and Psychopathology, 20(3), 899-911. doi:10.1017/S0954579408000436

Blair, C., \& Raver, C. C. (2014). Closing the achievement gap through modification of neurocognitive and neuroendocrine function: Results from a cluster randomized controlled trial of an innovative approach to the education of children in kindergarten. PLOS One, 9(11), 1-13. doi:10.1371/journal. pone. 0112393

Bongers, I. L., Koot, H. M., van der Ende, J., \& Verhulst, F. C. (2003). The normative development of child and adolescent problem behavior. Journal of Abnormal Psychology, 112(2), 179-192. doi:10.1037/0021-843X.112.2.179

Bornstein, M. H., Hahn, C.-S., \& Haynes, O. M. (2004). Specific and general language performance across early childhood: Stability and gender considerations. First Language, 24(3), 267-304. doi:10.1177/0142723704045681

Broidy, L. M., Nagin, D. S., Tremblay, R. E., Bates, J. E., Brame, B., Dodge, K. A., . . . Vitaro, F. (2003). Developmental trajectories of childhood disruptive behaviors and adolescent delinquency: A six-site, cross-national study. Developmental Psychology, 39(2), 222-245. doi:10.1037/0012-1649.39.2.222

Bronson, M. B. (2000). Self-regulation in early childhood: Nature and nurture. New York: The Guilford Press.

Brownlie, E. B., Beitchman, J. H., Escobar, M., Young, A., Atkinson, L., Johnson, C., . . Douglas, L. (2004). Early language impairment and young adult delinquent and aggressive behavior. Journal of Abnormal Child Psychology, 32(4), 453467. doi:10.1023/B:JACP.0000030297.91759.74

Calkins, S. D., \& Keane, S. P. (2009). Developmental origins of early antisocial behavior. Development and Psychopathology, 21(4), 1095-1109. doi:10.1017/S095457940999006X

Campbell, S. B. (2002). Behavior problems in preschool children: Clinical and developmental issues (2nd ed.). New York: The Guilford Press.

Campbell, S. B., Spieker, S., Vandergrift, N., Belsky, J., Burchinal, M., \& The NICHD Early Child Care Research Network. (2010). Predictors and sequelae of trajectories of physical aggression in school-age boys and girls. Development and Psychopathology, 22(1), 133-150. doi:10.1017/ S0954579409990319

Cantwell, D. P., \& Baker, L. (1991). Psychiatric and developmental disorders in children with communication disorder. Washington, DC: American Psychiatric Press.

Carlson, S. M., \& Beck, D. M. (2009). Symbols as tools in the development of executive function. In A. Winsler, C. Fernyhough, \& I. Montero (Eds.), Private speech, executive functioning, and the development of verbal self-regulation (pp. 163-175). New York: Cambridge University Press. doi:10.1017/ CBO9780511581533.014

Carlson, S. M., Moses, L. J., \& Claxton, L. J. (2004). Individual differences in executive functioning and theory of mind: An investigation of inhibitory control and planning ability. Journal of Experimental Child Psychology, 87(4), 299-319. doi:10.1016/j.jecp.2004.01.002

Cohen, N. J., Vallance, D. D., Barwick, M., Im, N., Menna, R., Horodezky, N. B., \& Isaacson, L. (2000). The interface between ADHD and language impairment: An examination of language, achievement, and cognitive processing. The Journal of Child Psychology and Psychiatry, 41(3), 353-362. doi:10.1017/S0021963099005442

Coie, J. D., \& Dodge, K. A. (1998). Aggression and antisocial behavior. In W. Damon \& N. Eisenberg (Eds.), Handbook of child psychology: Social, emotional, and personality development (5th ed., Vol. 3, pp. 779-862). Hoboken, NJ: John Wiley \& Sons, Inc.

Diamond, A., Barnett, W. S., Thomas, J., \& Munro, S. (2007). Preschool program improves cognitive control. Science, 318(5855), 1387-1388. doi:10.1126/science.1151148

Eisenberg, N., Guthrie, I. K., Fabes, R. A., Shepard, S., Losoya, S., Murphy, B. C., . . . Reiser, M. (2000). Prediction of elementary school children's externalizing problem behaviors from attentional and behavioral regulation and negative emotionality. Child Development, 71(5), 1367-1382. doi:10.1111/1467-8624.00233

Else-Quest, N. M., Hyde, J. S., Goldsmith, H. H., \& Van Hulle, C. A. (2006). Gender differences in temperament: A 
meta-analysis. Psychological Bulletin, 132(1), 33-72. doi:10.1037/0033-2909.132.1.33

Fernyhough, C. (2010). Vygotsky, Luria, and the social brain. In B. Sokol, U. Müller, J. Carpendale, A. Young, \& G. Iarocci (Eds.), Self and social regulation: Social interaction and the development of social understanding and executive functions (pp. 56-79). New York: Oxford University Press.

Fuhs, M. W., \& Day, J. D. (2011). Verbal ability and executive functioning development in preschoolers at Head Start. Developmental Psychology, 47(2), 404-416. doi:10.1037/ a0021065

Hay, D. F. (2007). The gradual emergence of sex differences in aggression: Alternative hypotheses. Psychological Medicine, 37(11), 1527-1537. doi:10.1017/S0033291707000165

Hughes, C., \& Ensor, R. (2011). Individual differences in growth in executive function across the transition to school predict externalizing and internalizing behaviors and self-perceived academic success at 6 years of age. Journal of Experimental Child Psychology, 108(3), 663-676. doi:10.1016/ j.jecp.2010.06.005

Hughes, C., Ensor, R., Wilson, A., \& Graham, A. (2009). Tracking executive function across the transition to school: A latent variable approach. Developmental Neuropsychology, 35(1), 20-36. doi:10.1080/87565640903325691

Jacques, S., \& Zelazo, P. D. (2005). Language and the development of cognitive flexibility: Implications for theory of mind. In J. W. Astington \& J. A. Baird (Eds.), Why language matters for theory of mind (pp. 144-162). New York: Oxford University Press.

Keenan, K., \& Shaw, D. (1997). Developmental and social influences on young girls' early problem behavior. Psychological Bulletin, 121(1), 95-113. doi:10.1037/0033-2909.121.1.95

Lonigan, C. J., Spiegel, J. A., Goodrich, J. M., Morris, B. M., Osborne, C. M., Lerner, M. D., \& Phillips, B. M. (2017). Does preschool self-regulation predict later behavior problems in general or specific problem behaviors? Journal of Abnormal Child Psychology, 45(8), 1491-1502. doi:10.1007/s10802-0160260-7

McClelland, M. M., \& Cameron, C. E. (2012). Self-regulation in early childhood: Improving conceptual clarity and developing ecologically valid measures. Child Development Perspectives, 6(2), 136-142. doi:10.1111/j.17508606.2011.00191.x

McClelland, M. M., Cameron, C. E., Connor, C. M., Farris, C. L., Jewkes, A. M., \& Morrison, F. J. (2007). Links between behavioral regulation and preschoolers' literacy, vocabulary, and math skills. Developmental Psychology, 43(4), 947-959. doi:10.1037/0012-1649.43.4.947

Petersen, I. T., Bates, J. E., D’Onofrio, B. M., Coyne, C. A.,
Lansford, J. E., Dodge, K. A., . . Van Hulle, C. A. (2013). Language ability predicts the development of behavior problems in children. Journal of Abnormal Psychology, 122(2), 542-557. doi:10.1037/a0031963

Pisoni, D. B., Conway, C. M., Kronenberger, W. G., Horn, D. L., Karpicke, J., \& Henning, S. C. (2008). Efficacy and effectiveness of cochlear implants in deaf children. In M. Marschark \& P. C. Hauser (Eds.), Deaf cognition: Foundations and outcomes (pp. 52-101). New York: Oxford University Press.

Roben, C. K. P., Cole, P. M., \& Armstrong, L. M. (2013). Longitudinal relations among language skills, anger expression, and regulatory strategies in early childhood. Child Development, 84(3), 891-905. doi:10.1111/cdev.12027

Schoemaker, K., Mulder, H., Deković, M., \& Matthys, W. (2013). Executive functions in preschool children with externalizing behavior problems: A meta-analysis. Journal of Abnormal Child Psychology, 41(3), 457-471. doi:10.1007/s10802012-9684-x

Sulik, M. J., Blair, C., Mills-Koonce, R., Berry, D., Greenberg, M., \& The Family Life Project Investigators. (2015). Early parenting and the development of externalizing behavior problems: Longitudinal mediation through children's executive function. Child Development, 86(5), 1588-1603. doi:10.1111/ cdev. 12386

van Elk, M., van Schie, H. T., Zwaan, R. A., \& Bekkering, H. (2010). The functional role of motor activation in language processing: Motor cortical oscillations support lexicalsemantic retrieval. Neuroimage, 50(2), 665-677. doi:10.1016/ j.neuroimage.2009.12.123

Vygotsky, L. S. (1987). Thinking and speech (N. Minick, Trans.). In R. W. Rieber \& A. S. Carton (Eds.), The collected works of L. S. Vygotsky. Vol. 1: Problems of general psychology (pp. 37-285). New York: Plenum Press. (Original work published in 1934). doi:10.1007/978-1-4613-1655-8

Weiland, C., Barata, M. C., \& Yoshikawa, H. (2014). The cooccurring development of executive function skills and receptive vocabulary in preschool-aged children: A look at the direction of the developmental pathways. Infant and Child Development, 23(1), 4-21. doi:10.1002/icd.1829

Wright, J. P., \& Beaver, K. M. (2005). Do parents matter in creating self-control in their children? A genetically informed test of Gottfredson and Hirschi's theory of low self-control. Criminology, 43(4), 1169-1202. doi:10.1111/j.17459125.2005.00036.x

Yew, S. G. K., \& O'Kearney, R. (2013). Emotional and behavioural outcomes later in childhood and adolescence for children with specific language impairments: Meta-analyses of controlled prospective studies. The Journal of Child Psychology and Psychiatry, 54(5), 516-524. doi:10.1111/ 
jcpp.12009

\section{In Korean}

Chang, H., \& Park, H. I. (2015). Self-regulation and psychosocial adjustment in Korean children: A meta-analysis. The Korean Journal of Developmental Psychology, 28(1), 1-32.

Choi, Y., Choi, M., \& Nam, M. (2013). Re-examination of the relationships between socioeconomic status and the development of inhibitory control among preschool Korean children. The Korean Journal of Developmental Psychology, 26(4), 107-123.

Kim, S.-H. (2014). The moderating effects of the teacher-child relationship on the relationship between young children's self-control and behavior problems. Korean Journal of Child Studies, 35(3), 31-47. doi:10.5723/kjcs.2014.35.3.31

Kim, Y., Hong, K., Kim, K., Jang, H., \& Lee, J. (2009). ReceptiveExpressive Vocabulary Test (REVT) guidelines. Seoul: Seoul Community Rehabilitation Center.

Kim, Y., Jang, H., Lim, S., \& Baek, H. (1995). Picture vocabulary test. Seoul: Seoul Community Rehabilitation Center.

Oh, K., \& Kim, Y. (2010). Manual for the ASEBA school-age forms. Seoul: Huno.

Park, Y.-H., \& Kim, S.-G. (2017). The relation of young children's externalizing behavior problems and language competencies: A focus on the mediated effect of peer play interactions. Early Childhood Education Research \& Review, 21(5), 219-238.

Seo, M. (2011). A meta-analysis of the gender differences and variables related to overt and relational aggression in children and adolescents. Korean Journal of Child Studies, 32(3), 143-162. doi:10.5723/KJCS.2011.32.3.143

Son, H., \& Choi, Y. (2011). Relationships between preschooler's sentence processing ability and executive functions. The Korean Journal of Developmental Psychology, 24(3), 87-104.

Suh, M.-O. (2004). A validation of the Korean version of the Social Skill Rating System for preschool level (K-SSRS: Teacher and parent forms). Journal of Early Childhood Education, 24(2), 223-242.

\section{ORCID}

Jinna Chung http://orcid.org/0000-0002-3290-1327

Revision received May 27, 2019

Accepted June 1, 2019 